\title{
Affective Responses as Guides to Category-Based Inferences ${ }^{1}$
}

\author{
Paula M. Niedenthal ${ }^{2}$ and Nancy Cantor \\ The University of Michigan
}

Initial nonconscious affective reactions to a target individual may influence a perceiver's selection from among descriptively plausible categories with which to organize his impression of the target. Specifically, a perceiver may be more likely to employ a category that is consistent, in affective tone, with the tone of his affective reaction. Subjects in two studies were exposed to photographs of faces of target individuals. Degree of preference for the faces was manipulated, outside of subjects' awareness, by varying the state of pupillary dilation. Participants in Study One reported that verbal descriptions that characterized positively (compared to negatively) evaluated category prototypes were more likely to be descriptive of targets with dilated pupils. Similarly, participants judged descriptions that characterized negatively (compared to positively) evaluated prototypes as more likely to be descriptive of targets with constricted pupils. In Study Two, subjects' recall of personality descriptions that were (evaluatively) inconsistent with their initial affective response to the target was superior to their recall of descriptions that were (evaluatively) consistent with the tone of their initial response. The data are interpreted as evidence for the importance of nonconscious affective reactions in guiding the process of impression formation.

Social perceivers frequently respond to others' nonverbal affective cues, even those cues to which they are not consciously attending (Schneider, Hastorf, \& Ellsworth, 1979; Argyle \& Cook, 1976; Duncan \& Niederehe, 1974; Ekman,

\footnotetext{
${ }^{1}$ The authors gratefully acknowledge Pam Adelmann, Mark Baldwin, Aaron M, Brower, Susan Fiske, Hazel Markus, Julie K. Norem, D. W. Rajecki, Carolin Showers, and Robert Zajonc for their helpful comments on earlier drafts of this manuscript. Parts of this paper were presented at the Meetings of the American Psychological Association, Toronto, August 1984. ${ }^{2}$ Address all correspondence to Paula Niedenthal, 426 Thompson Street, University of Michigan, 5267 Institute for Social Research, Ann Arbor, Michigan 48106.
} 
1972; Ellsworth \& Ross, 1976; Mehrabian, 1972). A well-known example of this is the affective reaction to variations in pupillary dilation. Individuals tend to prefer people with dilated pupils (as demonstrated both behaviorally and physiologically) and are less inclined toward people with constricted pupils. In addition, individuals make positive attributions about people whose pupils are dilated and negative attributions about people whose pupils are constricted, presumably without knowing that they are doing so (Flade \& Lindner, 1979; Hess, 1965, 1975; Hicks, Williams, \& Ferrante, 1979a, 1979b; Stass \& Willis, 1967; Tarrahian \& Hicks, 1979).

The importance of automatic, stimulus-based affective reactions in impression formation has received little attention since cognitive social psychologists focused on the affective outcomes of cognitive operations, such as the category-based evaluations that follow social categorization (e.g., Fiske \& Pavelchak, 1985; but see Zajonc, 1980). This may be an important omission. It seems plausible to suspect that an initial nonconscious affective reaction to a person can guide a perceiver's selection from among available descriptive categories with which to organize his or her cognitive representation of the person.

A long history of research has already demonstrated order effects in the impact of information (i.e., personality attributes) in the process of impression formation. Typically, a primacy effect is observed such that the first pieces of descriptive information that a perceiver obtains influence the evaluation of subsequently learned information (Hamilton \& Zanna, 1974; Asch, 1946; Stewart, 1965). There are good reasons to assume that primary affective reactions create similar interpretive or inference sets.

Recent approaches to modeling the representation of social knowledge in memory support this contention. Person memory, in particular, is now thought to be organized around emotion "nodes" or, alternatively, to be "tagged" by affective memory codes (Bower, 1981; Clark \& Isen, 1982; Fiske, 1982). While studies have demonstrated that retrieval of categorically related "hot" material is facilitated by the presentation of semantic primes to the category, it is theoretically just as likely that the material can be cued by a reexperience of the organizing affect-perhaps in response to something about a target person (Bower, 1981; Fiske \& Pavelchak, 1986; Lang, 1979).

This proposal complicates, but is not at odds with, current reformulations of the impression formation process, such as that described by Fiske (1982; Fiske \& Pavelchak, 1986). In Fiske's view, impression formation is a two-stage process that starts with the perceiver's attempt to form a cognitive representation of a target by comparison of the target's personal attributes to those that characterize a familiar social cateogry in memory. If the individual seems to be a good representative of a particular category, then that classification recruits a "category-based" affective impression. As we have 
implied, this might not be the whole story. A different type of affect, a general, stimulus-based affective response, may also contribute to the discrimination of the most suitable person categories in memory. That is, the affective quality of one's perception (however nonconscious it is) may operate in the initial phases of impression formation to preselect, or at least delimit, in terms of their affective tone, the most plausible categories for organizing an impression.

\section{STUDY ONE}

In the first experiment presented here we test this affective feature similarity hypothesis. In order to isolate the role of affective reactions in guiding social categorization, we manipulated affect by varying the pupillary dilation cues of the target stimuli. Pupillary dilation was thus the only basis for distinguishing among possible candidates for certain social categories.

Subjects in Study One were presented with a series of slides of faces of men and women with constricted (negative affect) or dilated (positive affect) pupils. As they viewed the slides, subjects judged the likelihood that descriptions composed of features of favorably or unfavorably evaluated social categories characterized the individuals they saw. We suspected that descriptions of the prototypes of favorable categories would be judged as more likely to be descriptive of targets with dilated pupils and that descriptions of the prototypes of unfavorable categories would be considered more characteristic of targets with constricted pupils.

\section{Method}

\section{Materials}

Prototype Categories. Category labels were generated by 10 pretest subjects, undergraduates at the University of Michigan, who were asked to list as many "kinds of people" as they could think of who fit the following specifications: feel negatively toward/male, feel negatively toward/female, feel positively toward/male, feel positively toward/female. Subjects later engaged in an open discussion, led by the experimenter, in which three category labels for each combination of evaluation and gender (12 in all) were unanimously agreed to be both familiar and consensually evaluated. Category labels are presented in Table I. It is important to note that these labels, which include affectively "loaded" adjectives, were used only to elicit the prototype descriptions described below. Subjects in the final stage of Study 
Table I. Category Labels for Favorable and Unfavorable Male and Female Prototypes

\begin{tabular}{lll}
\hline & \multicolumn{2}{c}{ Category affect } \\
\cline { 2 - 3 } Gender & \multicolumn{1}{c}{ Favorable } & \multicolumn{1}{c}{ Unfavorable } \\
\hline Male & "Cool" priest & Scheming politician \\
& Recreational sportsman & Cult member \\
& Young father & Heroin pusher \\
Female & Generous mother & Prissy librarian \\
& Helpful stewardess & "Airhead" \\
& Day care center employee & Haughty saleswoman \\
\hline
\end{tabular}

One were exposed to the descriptions without the category labels. These descriptions, then, served to prime the category.

Prototype Descriptions. Prototype descriptions were derived from the responses of an independent sample of 25 subjects ( 13 males, 12 females). Twelve subjects were run in one session and were asked to list the typical behaviors, attitudes and preferences, physical characteristics, and personality characteristics of each of six of the person categories from among those selected for use in the study. Thirteen subjects attended a separate session and completed the same task for the remaining six person categories.

Thirty-six prototype descriptions (three for each category) were constructed by combining one prototypical behavior, one attitude or preference, one physical feature, and one personality characteristic into a brief and comprehensible statement. An attribute was included if it had been mentioned by at least two subjects. Three naive judges correctly identified the statements as descriptive of the appropriate category with $86 \%$ accuracy, on average. Four descriptions (one for each of four category prototypes) that accounted for most of this error were discarded. Samples of the thirty-two remaining prototype descriptions are presented in Table II.

These same subjects also rated the "typical member" of each category on five dimensions: positivity, attractiveness, intelligence, honesty, and comfortableness. Person categories selected initially as positive concepts for both genders were judged significantly more likely to elicit feelings of positivity than the categories selected to elicit feelings of negativity $(p$ 's $<.01)$. The typical members of the positive categories were also rated more attractive, friendly, intelligent, honest, and comfortable than were typical members of the negative categories $(p$ 's $<.01)$.

\section{Subjects}

A total of 45 University of Michigan undergraduates (23 males, 22 females) participated in Study One. Voluntary experimental participation entitled subjects to partial credit toward a course requirement. 
Table II. Personality Descriptions That Prime Favorable and Unfavorable Category Prototypes

\begin{tabular}{|c|c|}
\hline Prototype & Description \\
\hline $\begin{array}{l}\text { Generous } \\
\text { mother }\end{array}$ & $\begin{array}{l}\text { She does charity work, is inventive, has warm, soft } \\
\text { hands, and supports social programs. }\end{array}$ \\
\hline $\begin{array}{l}\text { Prissy } \\
\text { librarian }\end{array}$ & $\begin{array}{l}\text { She blindly observes guidelines, is judgmental, is a } \\
\text { conservative dresser, and doesn't like excitement. }\end{array}$ \\
\hline $\begin{array}{l}\text { Scheming } \\
\text { politician }\end{array}$ & $\begin{array}{l}\text { He tries to con people into things, is ambitious, wears } \\
\text { tailored suits, and likes being in the spotlight. }\end{array}$ \\
\hline Young father & $\begin{array}{l}\text { He spends a lot of time with his wife and kids, is } \\
\text { humorous, never frowns, and likes to drink beer. }\end{array}$ \\
\hline $\begin{array}{l}\text { Helpful } \\
\text { stewardess }\end{array}$ & $\begin{array}{l}\text { She goes dancing at night, has a sunny personality, } \\
\text { stays in shape, and is confident when talking to } \\
\text { strangers. }\end{array}$ \\
\hline Cult member & $\begin{array}{l}\text { He is into meditation, is not easily of fended, is } \\
\text { physically weak, and believes he has found the } \\
\text { right way to live. }\end{array}$ \\
\hline "Airhead" & $\begin{array}{l}\text { She says stupid things in conversation, is absent- } \\
\text { minded, has a bouncy walk, and likes expensive } \\
\text { gifts. }\end{array}$ \\
\hline Heroin pusher & $\begin{array}{l}\text { He is driven by a desire for money, is paranoid, is } \\
\text { unhealthy, and is unconcerned about the future. }\end{array}$ \\
\hline $\begin{array}{l}\text { Day care center } \\
\text { employee }\end{array}$ & $\begin{array}{l}\text { She reads stories to children, is very sincere, speaks } \\
\text { softly, and likes to lead a slow-paced life. }\end{array}$ \\
\hline $\begin{array}{l}\text { Recreational } \\
\text { sportsman }\end{array}$ & $\begin{array}{l}\text { He always gets up early in the morning, is } \\
\text { enthusiastic, makes physical contact when speaking, } \\
\text { and likes free time. }\end{array}$ \\
\hline "Cool" priest & $\begin{array}{l}\text { He often talks to young people, is empathetic, is } \\
\text { physically strong, and supports the use of birth } \\
\text { control. }\end{array}$ \\
\hline $\begin{array}{l}\text { Haughty } \\
\text { saleswoman }\end{array}$ & $\begin{array}{l}\text { She easily avoids noticing people, has a domineering } \\
\text { personality, rarely shows emotions, and likes } \\
\text { wealthy people. }\end{array}$ \\
\hline
\end{tabular}

\section{Procedure}

Three to five subjects attended each experimental session. Upon their arrival at the experimental room, subjects were seated approximately 6 feet in front of a projector screen and were provided with the following instructions: "We are interested in how people form impressions and make inferences about other people. Today you will see a series of 32 slides of people's faces. Each slide will appear more than once. After you have viewed each slide for ten seconds, I will read a brief statement that could be descriptive of the person in the slide. Your task is to decide how likely it is that the description is in fact true of the person you see."

After viewing the slides and indicating their likelihood ratings on scales from 1 (not at all likely) to 7 (very likely), subjects were debriefed and thanked for their participation. 


\section{Design}

A within-subjects $2 \times 2$ (Prototype $\times$ Affect) experimental design was employed. All subjects were exposed to eight stimulus persons four times each for a total of 32 exposures. Of the eight stimulus persons, subjects saw slides of four persons (two males, two females) whose pupils were (consistently) dilated and four persons whose pupils were constricted (Figure 1). Two positive and two negative prototype descriptions (without labels) were paired with each stimulus person across the four exposures. Thus, all subjects heard both favorable and unfavorable descriptions ostensibly descriptive of targets with both dilated and constricted pupils.

Four orders of slide presentation, description-stimulus person combination, and pupillary dilation were constructed and counterbalanced across experimental sessions.

\section{Results and Discussion}

The design of the present experiment allowed us to test the hypothesis that target individuals who elicit positive affect are more likely to be
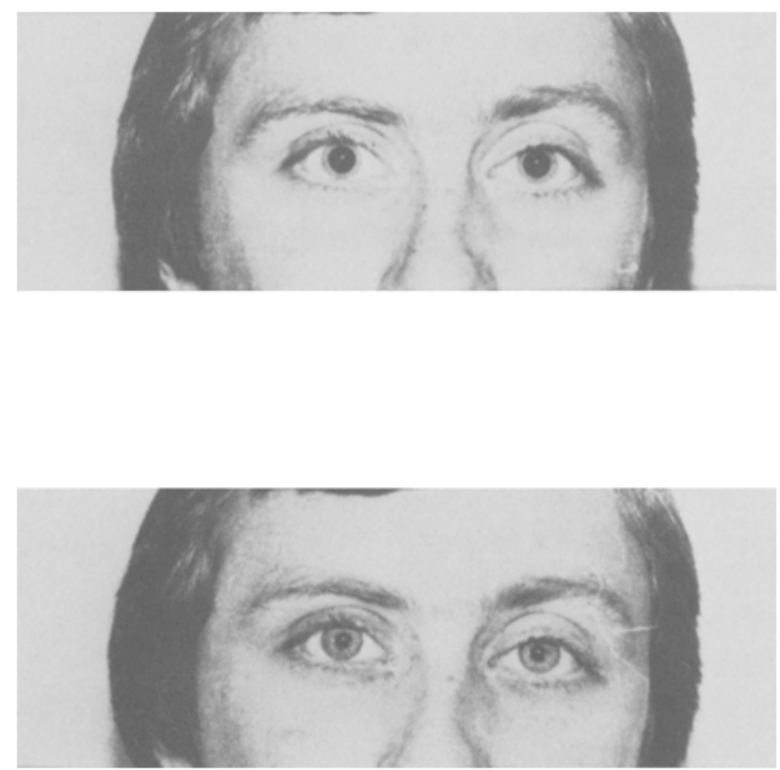

Fig. 1. Face of a target individual with dilated and constricted pupils. 
categorized in positive categories whereas targets who elicit negative affect are more likely to be categorized in negative ones. Four average likelihood rating scores were calculated for each subject: the likelihood that favorable prototype descriptions characterized targets with dilated pupils, the likelihood that favorable prototype descriptions characterized targets with constricted pupils, the likelihood that unfavorable prototype descriptions characterized targets with dilated pupils, and the likelihood that unfavorable prototype descriptions characterized targets with constricted pupils. These data were analyzed in a $2 \times 2$ (Prototype $\times$ Affect) repeated-measures ANOVA. A significant Prototype $\times$ Affect interaction was obtained $(F(1,42)=18.26, p<.001)$. In planned comparisons, favorable descriptions were rated as slightly more likely to be true of individuals with dilated pupils $(M=4.33)$ than of individuals with constricted pupils $(M=4.08, t(42)=1.85, p=<.07)$. Similarly, unfavorable prototype descriptions were judged as more likely to be descriptive of target individuals with constricted pupils $(M=4.17)$ than of targets with dilated pupils $(M=3.61, t(42)=4.79, p<.001)$.

The findings of the first experiment lend support for the hypothesized influence of initial affective reactions on the use of social categories. In this case, the tendency to represent a person as a member of a particular social category was influenced by the prior manipulation of state of pupillary dilation, a nonverbal cue to positivity-negativity. Of course, in everyday experience, information about the probability of a person representing a member of a given category is constrained partly by context, age, and other clues that work to provide the perceiver with general expectations: A party guest may expect to see "chic" people when at a party thrown by his more selfconsciously sophisticated friends. But whether he categorizes a woman with a particularly commanding presence as "neurotic and intrusive" or "provocative and exciting" may depend on his prior affective reaction to her. Indeed, it seems that an individual will judge another person as a "better" member of a particular social category if his or her affective response to the target, even if outside of awareness, is consistent (rather than inconsistent) with his or her feelings about the category prototype.

This argument should be distinguished from work on the impact of mood on cognitive processes, such as recall of semantic material, problem solving, and object categorization (Bower, 1981; Isen, Johnson, Mertz, \& Robinson, 1985; Teasdale \& Fogarty, 1979). The results of the first study demonstrate constraints on categorization posed by the perceiver's response to affectively informative properties of the target, not necessarily the effects of the perceiver's current mood per se. In most investigations of the effects of mood on cognitive processing, there is no connection between the information used in the mood induction procedure and the material being committed to memory or decision making. Moreover, in the present study, subjects were exposed to targets with both dilated and constricted pupils. 
Mood state is usually thought to last longer than a period of some seconds (see Isen, 1984, for a definition of mood state).

A stimulus-based affect approach to the use of social categories emphasizes the contribution of initial preference responses to successful categorization. The affective component of a category may, in some cases, be central enough to the essential definition of the concept to be a critical diagnostic feature; initial affective reactions to others may prepare the perceiver to classify a target in an affectively congruent category. But what happens if the perceiver's snap judgment is "wrong"? Another way to test the power of initial preferences to guide categorization is to present the perceiver with hypothesis-disconfirming evidence.

\section{STUDY TWO: AFFECTIVE FEATURE DISCREPANCY - EFFECTS ON MEMORY FOR DESCRIPTIVE INFORMATION}

To set up the problem by way of the previous example, suppose that at some level our party-goer experiences the unfamiliar female guest as highly approachable. If the experience indeed recruits evaluatively consistent expectations, what would happen if a friend confided that this woman was, in fact, quite emotionally distant and manipulative, classifying her as something of a "sociopath"?

Past research has shown that when a perceiver receives (semantic) information that is inconsistent with a previously instantiated representation of a person, he or she relinquishes the category-based representation and works with the inconsistencies in formulating a revised impression of the target (Hastie, 1980; Hastie \& Kumar, 1979; Hemsley \& Marmurek, 1982). Since cognitive work is created by the need to make sense of material not easily subsumed within an existing category or schema, recall of that schemainconsistent material is very good-typically superior to schema-consistent material (Brewer, Dull, \& Lui, 1981; Sentis \& Burnstein, 1979). If initial affective reactions guide the use of affect-laden categories, then we should be able to show parallel effects for recall of descriptive information that is evaluatively inconsistent (vs. consistent) with the affect-recruited category. The strongest interpretation of such a finding would argue that affective responses instantiate concepts that can then be contradicted with evaluatively inconsistent semantic information. A more moderate, and plausible, explanation follows from data reported by Fiske and Pavelchak (1986). They demonstrated that when a target seems to fit an available category, a rapid, category-based evaluation is generated by the perceiver. However, if the target does not fit any category well, the perceiver must construct an impression that is based on a consideration of each attribute known to be true of the target. Memory for the characteristics of the target should, therefore, be better 
when the target does not seem to fit any particular social category. An additional way to test the hypothesis that affective reactions guide social categorization, therefore, is to compare recall for descriptions of targets who evoke initial affective responses that conflict with the evaluative tone of those descriptions with recall for attributes of targets who elicit consistent affective reactions. Superior recall for features of targets who evoke affective responses that are inconsistent with the evaluation of the category described by their personal attributes would suggest that the perceiver has already generated category-based inferences based on his affective reaction and that the inconsistent information has invalidated categorization.

In Study Two, we measured recall for descriptions of typical members of favorable and unfavorable person categories that were ostensibly characteristic of target individuals toward whom subjects felt initially more or less positively. Subjects were presented with photographs of some of the same targets seen in the previous experiment and were asked to complete evaluative impression questionnaires about each target. Subjects were then unexpectedly asked to evaluate the same targets again. This time the photographs were paired with prototype descriptions made up of five features that, taken together, primed a prototype of a familiar category that was either consistent or inconsistent, in evaluative tone, with the appraisal evoked by pupillary dilation. In an unannounced memory test, subjects were asked to recall the descriptive information. We expected that when the evaluation of a category prototype, evoked by descriptive information, conflicted with the perceiver's initial affective appraisal of a social target, then the second evaluation would be generated in elemental rather than stereotyped mode. We predicted, therefore, that recall for items from evaluatively inconsistent personality descriptions would be superior to recall of elements of affectively consistent descriptions. Affectively consistent information should be evaluated in stereotyped affective mode and thus be relatively poorly recalled.

\section{Method}

Subjects

Subjects were 62 undergraduates from the University of Michigan who had not participated in the previous experiment. Voluntary experimental participation entitled subjects to partial credit toward a course requirement.

\section{Materials}

Four- by six-inch black-and-white photographs of the faces of two male and two female models (seen in the previous experiments), mounted 
on the right inside panel of $8^{\prime \prime} \times 14^{\prime \prime}$ cardboard folders, were used as target stimuli. Prototype descriptions were attached to the left inside panel of each folder and were covered with slips of $3^{\prime \prime} \times 5^{\prime \prime}$ paper that could be lifted to allow viewing of the typed information beneath. The descriptions were eight prototype descriptions (four positive, four negative; two from each genderspecified category) from the 32- original statements constructed for use in the prior study. An additional prototypical personality characteristic was added to each description so that all descriptions were composed of five feature items. For example, a description of a "haughty saleswoman" read: "She is friendly only to people like herself, is pushy, is inconsiderate, tries to look younger than she is, and likes expensive possessions." (Subjects were not shown the category labels.)

\section{Procedure}

Subjects were run in groups of four and were assigned to "partners" according to how they had arranged themselves, side-by-side, at a table upon arrival at the experimental laboratory. The ostensible purpose of the study was to explore "how people use different kinds of information to form and communicate impressions of others." Subjects were told that in the course of the experiment they would examine photographs and written descriptions of a variety of people, on the basis of which they would complete evaluation questionnaires. Next, subjects were erroneously led to believe that the sets of partners would exchange packets as part of a communication task later in the session. The ostensible communication task would require subjects to make inferences about the stimulus persons that the other set of partners had seen on the basis of the other partners' evaluation questionnaires. This manipulation was included to motivate subjects to form as well-integrated impressions as possible (Zajonc, 1960). Finally, each subject was given a large envelope and was asked to put his or her evaluation questionnaires inside upon completion.

\section{Evaluation One: Photographs Only}

In the first task, each pair of partners received four folders containing the target photographs, and each subject received four evaluation questionnaires. The evaluation questionnaires elicited subjects' ratings of their feelings of positivity toward the stimulus persons, and asked how comfortable the target made them feel, how likable they thought the target was, and how confident they were in their ratings of likability on scales from 1 to 7 (where $1=$ not at all positive, etc., $7=$ very positive, etc.). In addition, subjects 
provided responses to questions that read "Could this person make you feel: angry, afraid, happy, sad, excited, relaxed, disgusted, content, frustrated?" (where $1=$ not at all likely and $7=$ very likely).

Subjects opened the folders and viewed the photographs contained inside one at a time. They were given exactly 1 minute to examine the photograph and complete the evaluation questionnaire. When this process had been repeated four times, subjects were asked to return the closed folders to their original positions on the table in front of them.

\section{Evaluation Two: Photographs and Prototype Descriptions}

In the second task, subjects viewed the same four target individuals they had evaluated in the previous task. This time, however, subjects were asked to form their impressions on the basis of the faces in combination with the information on the left inside panel of the folders. Subjects read the descriptions for 10 seconds, closed the cover slip, and were allotted 1 minute in which to complete the evaluation questionnaires (identical to those seen in the first task) for their second evaluations. Photographs remained visible during the 1 -minute interval.

\section{Recall of Prototype Attributes}

Finally, subjects were unexpectedly asked to recall the person descriptions seen in the previous task and to be as accurate as possible in recalling the sense and the wording of the information. Subjects opened the folders again, viewed only the target photographs for 10 seconds each, closed the folder, and attempted to write as many items from the descriptions as they could remember within a 30 -second interval.

Upon completion of the third task, the experimenter announced that the experiment was over and apologized for leading the subjects to expect a final communication task. Subjects were then thoroughly debriefed and thanked for their participation.

\section{Design}

A within-subjects design was used. All subjects saw one stimulus person who represented an instance from each of the following prototype description/affect combinations: favorable description plus positive affect, i.e., dilated pupils (favorable-consistent); favorable description plus negative affect, i.e., constricted pupils (favorable-inconsistent); unfavorable prototype description plus negative affect (unfavorable-consistent); and unfavorable 
prototype description plus positive affect (unfavorable-inconsistent). In order to control for possible effects of memory for specific prototype descriptions, two different descriptions for each of the above conditions were employed and were counterbalanced across sessions. In addition, specific targetdescription combinations were also counterbalanced across sessions.

\section{Results and Discussion}

Analyses of the primary evaluation questionnaires provide some additional support for the pupillary dilation hypothesis (Hess, 1965, 1975; Hicks et al., 1979a, 1979b, Stass \& Willis, 1967; Tarrahian \& Hicks, 1979). Although all of the graduate student models were perceived as relatively likable ( $M=5.56$ on a 7-point scale), subjects were significantly more confident of their ratings of likability for persons with dilated ( $M$ $=5.73)$ compared to constricted pupils $(M=5.39, t=2.07, p<.05)$. Analyses of the specific reactions to the faces indicated that subjects thought that individuals with dilated pupils $(M=4.91)$ were more likely to make them excited than individuals with constricted pupils $(M=4.40, t=2.54$, $p<.02)$.

Recall items were coded as correct responses if they constituted exact or synonymous phrasing and communicated the evaluative tone of the original wording. Two judges who were blind to the affect cue (state of pupillary dilation in the associated photograph) scored the memory protocols separately; $96 \%$ agreement was observed. Final response scores were computed by subtracting the number of incorrectly recalled items from the number of correctly recalled items. Results of a $2 \times 2$ (Prototype $\times$ Affect) repeatedmeasures ANOVA revealed a significant interaction between Prototype and Affect, i.e., state of pupillary dilation of stimulus individual, $(F(1,61)=$ $8.06, p<.01)$. A main effect of Prototype was also obtained $(F(1,61)=$ $21.44, p<.001)$ : Subjects recalled more items from the unfavorable prototype descriptions $(M=2.124)$ than the favorable descriptions $(M=.949){ }^{3}$ The main effect for Affect was not significant.

Planned comparisons of recall of items that characterized a prototype evaluated in a manner consistent versus inconsistent with the affective reaction evoked by state of pupillary dilation of the target revealed the expected results. Subjects recalled more descriptive items from the favorableinconsistent $(M=1.23)$ than from the favorable-consistent target-description

\footnotetext{
${ }^{3}$ Superior recall for items from unfavorable, compared to favorable, categories probably represents a replication of past work on negativity biases (Kanouse \& Hanson, 1972).
} 


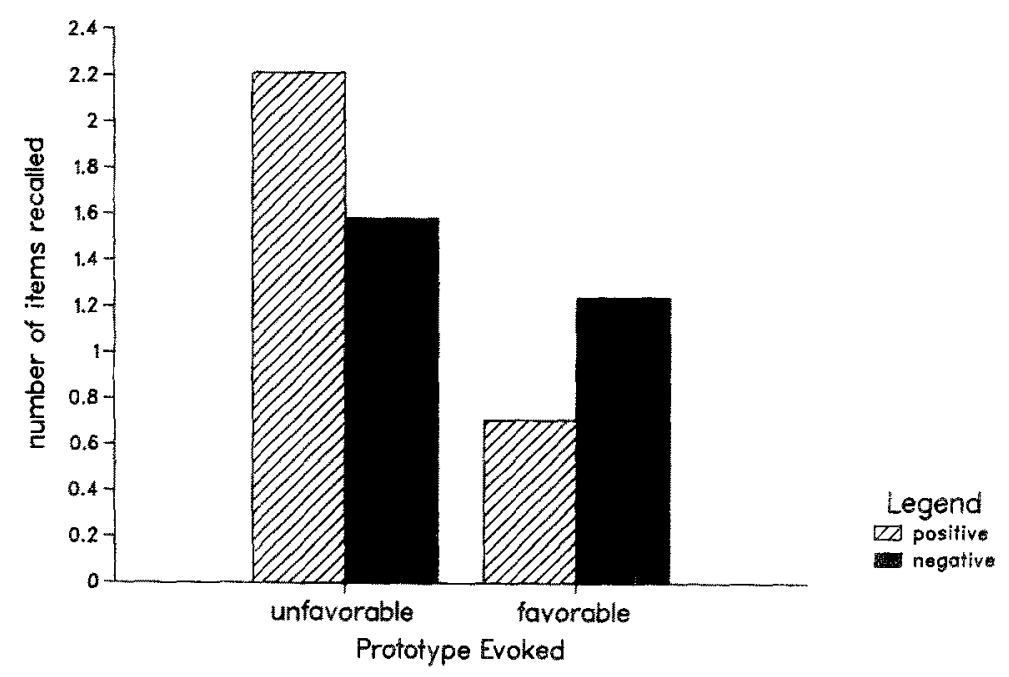

Fig. 2. Recall of characteristics of favorable and unfavorable prototypes descriptive of targets who evoked negative and positive affect.

combinations $(M=.701, F(1,61)=3.81, p=.05)$. Similarly, subjects recalled more items from the unfavorable-inconsistent $(M=2.209)$ than from the unfavorable-consistent target-description combinations $(M=1.58, F(1,61)$ $=4.17, p<.05$ ). These results are illustrated in Figure 2 .

In sum, subjects recalled more pieces of information from a favorable description of a stimulus person if that target generated a negative primary appraisal. Similarly, subjects recalled more items from an unfavorable description of a stimulus person who communicated positive affect. It seems that descriptive information evoking a prototype that is evaluated in a manner inconsistent with the perceiver's affective appraisal of a target is processed somewhat differently than is evaluatively consistent information.

One interpretation of this pattern of results is similar to that offered in past work on effects of schema-inconsistent material on memory in impression formation tasks (Brewer et al., 1981; Sentis \& Burnstein, 1979). Schema-inconsistent material demands attention and interpretation in order to be integrated to form a coherent concept of another person. Compared to schema-consistent information, which is more easily incorporated into a preexisting representation, inconsistent material becomes more salient and accessible for recall. Similarly, information that is discrepant with a prior affective reaction may have to be considered piecemeal in order for an overall impression to be formed. The importance of the present findings is that the only basis for a preexisting structure was the initial affective response to the target individuals. Although subjects probably had no specific descriptive 
category in mind, they seemed to be prepared to conceptualize the targets as members of certain affect-laden categories and later attended more to information that challenged that preparedness. Study Two, in combination with Study One, provides converging evidence to suggest that individuals respond to affective cues outside their awareness by considering affectively congruent social concepts to organize impressions of others.

\section{GENERAL DISCUSSION}

Do we consider people who evoke negative primary affect as candidates for our negative-affect social categories? It seems that we may. Global affective reactions, even those based on cues transmitted outside of conscious awareness, seem to recruit, or delimit, the categories of the "types" of people others may or may not be. The results of Study Two suggest that an inconsistency between initial affective impressions and the tone of a semantically evoked concept may prevent successful categorization of the target in the descriptive category and encourage piecemeal (rather than categorybased) impression formation. Although these studies do not directly test the effects of nonconscious stimulus-based affective reactions on the generation of category-based evaluation, taken together, they do provide the first step in demonstrating the role of affective responses in the use of stereotypes.

Theorists from Allport (1954) to Fiske (1982) have suggested that material in memory becomes associated with "labels of primary potency" or summary "affect nodes" through social learning or conditioning. Preferences for certain stimulus configurations may, too, be learned or conditioned (outside of awareness) such that automatic affective reactions, generated upon encountering another person, may depend on past experience (also see Leventhal, 1974, 1979). For exmple, people who move in an exaggerated jerky, nervous fashion could be members of a "mentally ill," "alcoholic," "drugdependent," or "high-jacker" category. After several experiences with people characterized by a lack of smooth muscle control, the sight of an example may invariably evoke an automatic, nonconscious, negative response in an observer. This response, in turn, may influence subsequent processing of descriptive material. Of course, the stimulus properties that implicate negative or positive impressions are probably countless. For example, there exists a body of evidence suggesting that the strength of an individual's attraction to babies is highly dependent upon the shape of the baby's face and the configuration of facial features (Hildebrandt \& Fitzgerald, 1979; Sternglanz, Gray, \& Murakami, 1977). 
Regardless of the stimulus-based origins of primary response, the findings reported here suggest that the social observer is prepared to see another person as an instance of one of a set of affectively laden categories that is congruent with the tone of that response. While these nonverbal cues may not evoke a discrete descriptive category, they may still be essential for the perception of a "successful" fit between a target and a particular category.

\section{REFERENCES}

Allport, G. W. (1954). The nature of prejudice. Cambridge, Massachusetts: Addison-Wesley. Argyle, M., \& Cook, M. (1976). Gaze and mutual gaze. Cambridge: Cambridge University Press. Asch, S. E. (1946). Forming impressions of personality. Journal of Abnormal and Social Psychology, 41, 258-290.

Bower, G. H. (1981). Mood and memory. American Psychologist, 36, 129-148.

Brewer, M. B., Dull, V., \& Lui, L. (1981). Perception of the elderly: Stereotypes as prototypes. Journal of Personality and Social Psychology, 41, 656-670.

Clark, M. S., \& Isen, A. M. (1982). Toward understanding the relationship between feeling states and behavior. In A. Hastorf \& A. M. Isen (Eds.), Cognitive social psychology. New York: Elsevier North-Holland Press.

Duncan, S. D., \& Niederehe, G. (1974). On signalling that it's your turn to speak. Journal of Experimental Psychology, 10, 234-247.

Ekman, P. (1972). Universals and cultural differences in facial expressions of emotions. In J. Cole (Ed.), Nebraska symposium on motivation. Lincoln: University of Nebraska Press.

Ellsworth, P. C., \& Ross, L. (1976). Intimacy in response to direct gaze. Journal of Experimental Social Psychology, 11, 592-613.

Fiske, S. T. (1982). Schema-triggered affect: Applications to social perception. In M. S. Clark \& S. T. Fiske (Eds.), Cognition and affect: The 17th annual Carnegie symposium. Hillsdale, New Jersey: Erlbaum.

Fiske, S. T., \& Pavelchak, M. A. (1986). Category-based versus piecemeal-based affect response: Developments in schema-triggered affect. In R. M. Sorrentino \& E. T. Higgins (Eds.), The handbook of motivation and cognition: Foundations of social behavior. New York: Guilford Press.

Flade, A., \& Lindner, G. (1979). Die Rolle der Pupillengrosse bei der Wahrnehmung von Personen. Zeitschrift für Experimentelle und Angewandte Psychologie, 26(3), 436-447.

Hamilton, D. L., \& Zanna, M. P. (1974). Context effects in impression formation: Changes in connotative meanings. Journal of Personality and Social Psychology, 29, 649-654.

Hastie, R. (1980). Memory for behavioral information that confirms or contradicts a personality impression. In R. Hastie, T. M. Ostrom, E. B. Ebbeson, R. S. Wyer, D. L. Hamilton, \& D. E. Carlton (Eds.), Person memory: the cognitive basis of perception. Hillsdale, New Jersey: Erlbaum.

Hastie, R., \& Kumar, P. A. (1979). Person memory: Personality traits as organizing principles in memory for behavior. Journal of Personality and Social Psychology, 37, 25-38.

Hemsley, R., \& Marmurek, P. (1982). Person memory: The processing of consistent and inconsistent information. Personality and Social Psychology Bulletin, 8, 433-438.

Hess, E. H. (1965). Attitude and pupil size. Scientific American, 222(4), 46-54.

Hess, E. H. (1975). The tell-tale eye. New York: Litton.

Hicks, R. A., Williams, S. L., \& Ferrante, F. (1979a). Eye color and the pupillary attributions of college students to happy and angry faces. Bulletin of the Psychonomic Society, 13(1), 55-56. 
Hicks, R. A., Williams, S. L., \& Ferrante, F. (1979b). Pupillary attribution of college students to happy and angry faces. Perceptual and Motor Skills, 48, 401-402.

Hildebrandt, K. A., \& Fitzgerald, H. E. (1979). Facial feature determinants of perceived infant attractiveness. Infant Behavior and Development, 2, 329-339.

Isen, A. M. (1984). Toward understanding the role of affect in cognition. In R. Wyer \& T. Srull (Eds.), Handbook of social cognition. Hillsdale, New Jersey: Erlbaum.

Isen, A. M., Johnson, M. M. S., Mertz, E., \& Robinson, G. F. (1985). The influence of positive affect on the unusualness of word associations. Journal of Personality and Social Psychology, 48, 1413-1426.

Kanouse, D. E., \& Hanson, L. R. (1972). Negativity in evaluations. In E. E. Jones et al. (Eds.), Attribution: Perceiving the causes of behavior. Morristown, New Jersey: General Learning Press.

Lang, P. J. (1979). Language, image and emotion. In P. Pliner, K. R. Plankstein, \& J. M. Spigel (Eds.), Perception of emotion in self and others (Vol. 5). New York: Plenum.

Leventhal, H. A. (1974). Emotions: A basic problem for social psychology. In C. Nemeth (Ed.), Social psychology: Classic and contemporary interactions. New York: Rand McNally.

Leventhal, H. A. (1979). A perceptual-motor processing model of emotion. In R. Pliner, K. R. Blankenstein, \& I. M. Spigel (Eds.), Advances in the study of communication and affect (Vol. 5). New York: Plenum.

Mehrabian, A. (1972). Nonverbal communication. Chicago: Aldine-Atherton,

Schneider, D. J., Hastorf, A. H., \& Ellsworth, P. C. (1979). Person perception. Reading, Massachusetts: Addison-Wesley.

Sentis, K. P., \& Burnstein, E. (1979). Remembering schema-consistent information: Effects of a balance schema on recognition memory. Journal of Personality and Social Psychology, 317, 2200-2211.

Stass, J. W., \& Willis, F. N. (1967). Eye contact, pupil dilation, and personal preference. Psychonomic Science, 7, 375-376.

Sternglanz, S. H., Gray, J. L., \& Murakami, M. (1977). Adult preferences for infantile facial features: An ethological approach. Animal Behavior, 25, 108-115.

Stewart, R. H. (1965). Effects of continuous responding on the order effect in personality impression. Journal of Personality and Social Psychology, l, 161-165.

Tarrahian, G. A., \& Hicks, R. A. (1979). Attributions of pupil size as a function of facial valence and age in American and Persian children. Journal of Cross-Cultural Psychology, 10(2), 243-250.

Teasdale, J. D., \& Fogarty, S. J. (1979). Differential effects of induced mood on retrieval of pleasant and unpleasant events from episodic memory. Journal of Abnormal Psychology, $88,248-257$.

Zajonc, R. B. (1960). The process of cognitive tuning in communication. Journal of Abnormal and Social Psychology, 61, 159-167.

Zajonc, R. B. (1980). Feeling and thinking: Preferences need no inferences. American Psychologist, 35, 151-175. 